University of Wollongong

Research Online

Faculty of Business - Papers (Archive)

Faculty of Business and Law

2013

Competition or collaboration? The effect of non-profit brand image on volunteer recruitment strategy

Melanie Randle

University of Wollongong, mrandle@uow.edu.au

Friedrich Leisch

University of Natural Resources and Life Sciences

Sara Dolnicar

University of Queensland, s.dolnicar@uq.edu.au

Follow this and additional works at: https://ro.uow.edu.au/buspapers

Part of the Business Commons

Research Online is the open access institutional repository for the University of Wollongong. For further information contact the UOW Library: research-pubs@uow.edu.au 


\title{
Competition or collaboration? The effect of non-profit brand image on volunteer recruitment strategy
}

\author{
Abstract \\ With increasing numbers of non-profit organizations and higher demand for a wider range of social \\ services, the need for volunteers has never been greater. There is general agreement that competition \\ within the sector is increasing, and this has led to organizations placing greater emphasis on building \\ strong brand images to differentiate themselves from competitors. However, there are also many \\ instances where non-profits have successfully collaborated with each other to achieve efficiencies and \\ meet objectives. The purpose of this exploratory study is to examine, which of these approaches - \\ competition or collaboration - is more appropriate for the challenge of volunteer recruitment. We use data \\ from an empirical study of 1415 Australians to investigate whether, based on perceived organizational \\ brand images, volunteering organizations compete with each other for volunteers or are seen as \\ complimentary. Results indicate that while consideration of organizations with certain brand images - \\ especially the Heroes image - means that donation of time to other volunteering organizations is unlikely, \\ other organizational brand images, such as that of being a local volunteering organization or one that \\ provides support to people experiencing difficulty are likely to be compatible, opening up valuable \\ opportunities for collaborative marketing for the purpose of volunteer recruitment.
}

This is a post-peer-review, pre-copyedit version of an article published in Journal of Brand Management. The definitive publisher-authenticated version Competition or collaboration? The effect of non-profit brand image on volunteer recruitment strategy. Journal of Brand Management, 20 (8), 689-704 is available online at: http://dx.doi.org/10.1057/bm.2013.9

\section{Keywords}

profit, non, effect, collaboration, strategy, competition, recruitment, volunteer, image, brand

\section{Disciplines}

Business

\section{Publication Details}

Randle, M., Leisch, F. \& Dolnicar, S. (2013). Competition or collaboration? The effect of non-profit brand image on volunteer recruitment strategy. Journal of Brand Management, 20 (8), 689-704. 


\title{
Competition or collaboration?
}

\section{The effect of non-profit brand image on volunteer recruitment strategy}

\begin{abstract}
With increasing non-profit organizations and higher demand for a wider range of social services the need for volunteers has never been greater. There is general agreement that competition within the sector is increasing, and this has led to organizations placing greater emphasis on building strong brand images to differentiate themselves from competitors. However, there are also many instances where non-profits have successfully collaborated with each other to achieve efficiencies and meet objectives. The purpose of this exploratory study is to examine which of these approaches - competition or collaboration - is more appropriate for the challenge of volunteer recruitment. We use data from an empirical study of 1,415 Australians to investigate whether, based on perceived organizational brand images, volunteering organizations compete with each other for volunteers or are seen as complimentary. Results indicate that while consideration of organizations with certain brand images - especially the Heroes image - means that donation of time to other volunteering organizations is unlikely, other organizational brand images, such as that of being a local volunteering organization or one that provides support to people experiencing difficulty are likely to be compatible, opening up valuable opportunities for collaborative marketing for the purpose of volunteer recruitment.
\end{abstract}

Keywords: brand image, competition, collaboration, non-profit marketing, volunteers 


\section{INTRODUCTION}

Traditionally, the third sector has operated largely in an environment of non-competition. Charity organizations viewed themselves as providing important social services, and other non-profit organizations as helping to contribute to the common good and fill perceived voids in public services (Pietroburgo and Wernet, 2004). More recently, and with the significant increase in the number of non-profit organizations operating in the sector, a more competitive mindset has developed which is based on the notion that non-profit organizations compete with each other for limited resources (Ewing and Napoli, 2005; Lindenberg and Dobel, 1999). Most commonly, these resources are financial (e.g. funding or voluntary donations) or take the form of unpaid labour (e.g. volunteers), and the nature of any competition often depends on the particular market being targeted by different organizations (e.g. if they are targeting businesses, individual citizens or both).

The concept of non-profit market competition has received attention from researchers seeking insight as to how to best apply traditionally commercial marketing concepts in the non-profit context. The objective of this application is to enable non-profits to operate more effectively in obtaining the resources required. From a marketing perspective, for example, this has included attention on the notion of non-profit brand image and brand personality (Chiagouris, 2005; Venable et al, 2005), market segmentation (Dolnicar and Randle, 2007a, 2007b), positioning and targeting (Haski-Leventhal and Meijs, 2011), customer orientation (Dolnicar and Lazarevski, 2009) and customer retention (Starnes and Wymer, 2001).

However, numerous examples can also be cited of non-profit organizations successfully collaborating with each other to improve efficiencies and achieve economies of scale. For instance, jointly applying for funding or pooling resources and expertise to deliver large scale 
programs that individual organizations would be unable to provide on their own (Rados, 1996). Scholarly attention in these areas has resulted in a body of evidence available to nonprofits to inform decision making regarding whether a collaborative or competitive approach is appropriate for the challenges they face (this body of work will be reviewed in detail in the next section).

One area for which there is currently little evidence to inform such decision making is the challenge of volunteer recruitment. Collaboration in this regard could be considered high risk because volunteers are free to choose and move between organizations and, in the worst case, large numbers of volunteers leaving an organization could spell the end of its existence. Consequently, evidence of the benefits of this type of collaboration must be substantially stronger to justify non-profits embracing this strategy.

On one hand, if a competitive viewpoint is taken, we assume that volunteers choose between non-profit organizations for experiences that are viewed as mutually exclusive. From this perspective organizations are assumed to compete for an individual volunteer's time, an assumption that has resulted in some organizations trying to entice volunteers away from other organizations. This approach is relatively expensive because it involves each organization developing and implementing their own marketing campaigns, which is often difficult for smaller organizations that typically have small budgets for marketing-related activities.

On the other hand, if a collaborative viewpoint is taken, we assume that some organizations are seen by volunteers as complimentary rather than exclusive. In this scenario it is possible that these organizations could jointly attract and share their volunteers. This is an interesting and potentially highly valuable avenue for investigation, particularly considering that more than $40 \%$ of volunteers donate time to more than one organization concurrently (Australian Bureau of Statistics, 2010). 
The aim of the present study is to explore whether there is potential for non-profit organizations to take a collaborative approach towards volunteer recruitment, a question that is investigated within the context of perceived organizational brand image. Specifically, we investigate whether people have similar images of different volunteering organizations which make them suitable collaborative partners for volunteer recruitment. Theoretically, this adds to our understanding of the structure of the volunteer marketplace and the role and importance of organizational brand image within the non-profit sector. Practically, this insight allows managers of volunteer organizations to re-think the way they approach volunteer recruitment, to have a more clear understanding of their and other organizations' brand images, and to take a more strategic approach to volunteer marketing.

\section{LITERATURE REVIEW}

\section{Understanding volunteers}

In the field of volunteering, many scholars have sought to answer two key questions: who volunteers and why do they do it? In term of who volunteers, the answer appears largely dependent on the activity involved and the context in which the volunteering occurs. For example, Schlesinger and Nagel (2013) found sporting club volunteers to have higher incomes, lower workloads, and children belonging to the club, while Randle and Dolnicar (2006) found environmental and animal rights volunteers more likely to be younger, male, unmarried and have no children. Volunteers have also been described as exhibiting particular psychological characteristics such as pro-social attitudes (Wymer, 1997) or a distinctive world view (Reed and Selbee, 2000). In their (2007a) study Randle and Dolnicar included both socio-demographic and psychographic characteristics to compare four segments of 
volunteers grouped according to the organizations they volunteered for. Significant differences between groups were found including, for example, that volunteers for humanitarian causes are likely to be older, female and concerned with helping the sick and disabled, while volunteers for recreational and youth clubs are more likely to be male and express less concern for personal and social issues. National-level studies in the US and Australia suggest that volunteers are likely to be female, middle-aged and married (Bureau of Labor Statistics, 2007; Lyons and Passey, 2005). These varied and seemingly contradictory findings highlight the need to clearly understand the specific group of volunteers of interest in order to then identify their defining characteristics.

The issue of why individuals volunteer has proven equally complex and varied according the individual involved. Traditionally, volunteering was associated with altruistic motivations such as wanting to help those less fortunate than oneself (Bussell and Forbes, 2002). However, more recently it has been acknowledged that many people volunteer because of benefits gained for themselves. These can be broad-ranging and include, for example, being able to socialize, meet new people, keep physically and mentally active and gain personal satisfaction from a job well done (Hibbert, Piacentini and Al Dajani, 2003). It is generally agreed that motivations are multifaceted and various theories have been proposed in an attempt to explain these. For example, Clary et al. (1998) proposed the Volunteer Functions Inventory (VFI) which identifies six functions served by volunteering and demonstrated that individuals typically nominate multiple motivations within and across functions when asked why they volunteer. Other social theories, such as the Affect Theory of Social Exchange (Lawler, 2001) are useful in understanding how volunteering, when it involves a feeling of mutual responsibility and interdependence (both between individual volunteers and the organization) can lead to shared positive emotional outcomes which result in volunteers returning time and time again. 
The challenge faced by non-profit organizations operating in a fast growing third sector is to identify the particular characteristics and motivations of the individuals likely to volunteer for their organization. Once this is known, customized marketing strategies can be developed that have the highest chance of successfully attracting these particular types of people.

\section{Non-profit collaboration}

The philosophical approach of collaboration within the non-profit sector stemmed from the ideological foundations of many non-profits which supported other groups working towards the common good. More recently, collaboration has been viewed as strategically desirable due to potential benefits such as cost savings and sharing of expertise and skills (Andreasen and Kotler, 2003; Sargeant and Jay, 2004). Collaboration has also enabled organizations to respond more effectively to institutional and governmental changes that affect the way nonprofits operate in the $21^{\text {st }}$ century (Provan, Isett and Milward, 2004).

These benefits of non-profit collaboration have attracted scholarly attention, with examination of the different types of collaborations that can occur. For example Guo and Acar (2005) drew on multiple previous typologies to identify eight forms of collaborative activities based on their degree of formality, ranging from simple information sharing to formal mergers, and identified characteristics of organizations likely to collaborate. They concluded that they are typically older, have larger budgets, have more Board-level links with other non-profits and operate in particular fields. Other empirical research has identified factors necessary for effective collaboration, such as a genuine ideology of cooperation, the need to encourage existing channels of interaction between the parties and the importance of reinforcing unity between the parties (Kaplan, 1986). 
While collaborations are often instigated by participating agencies because of the organizational benefits that result, they also occur because they are mandated by governments as a way of more efficiently using available resources to provide higher quality services (e.g. being required to jointly apply for funding or hospitals having to send patients to other hospitals if there are no available beds) (Rados, 1996). Despite the many advantages of the collaborative approach, some disadvantages have been identified such as a loss of organizational independence, a lack of resources available to maintain the collaborative relationship and perceived vulnerabilities associated with opening the organization up to outside scrutiny (York and Zychlinski, 1996).

Although collaboration has been advocated for some aspects of non-profit organization management, there is currently no evidence that non-profits have, or should, cooperate when it comes to recruiting volunteers. This is possibly due to the high value placed on attracting and retaining unpaid volunteers and a perceived high risk of volunteers switching organizations. Together, these factors have resulted in practitioners viewing collaborative recruitment strategies as largely unrealistic.

\section{Non-profit competition}

Those that take a competitive view of the third sector attribute this competition not only to the existence of more non-profit organizations and greater demand for social services (Bussell and Forbes, 2002), but also an increased need for funding and volunteers. Many nonprofits have been forced to set up for-profit businesses to help fund their charitable endeavors and this has also been blamed for the competitive mentality generally increasing (Rados, 1996). Sargeant (2005) suggests that non-profit organizations must adopt a mindset of 
“customer orientation” which involves continually monitoring their competitors and competitive environment in order to achieve a competitive advantage (p.39).

Specifically in relation to competition between volunteering organizations, Broadbridge and Horne (1996) assert that competition for volunteers' time is increasing and give specific recommendations to managers of non-profit charity retailers for how compete more effectively. These include having a clear understanding of volunteer information linkages, focusing not just on those types of individuals who already volunteer but being open-minded about new and different types of volunteers, and being deliberate in knowing and matching the motivations of volunteers with suitable activities.

Proponents of a competitive non-profit sector argue that it forces organizations to be more client-focused and provide higher quality social services. In addition, it encourages innovation and, ultimately, specific segments of the population are better served as organizations differentiate themselves in the marketplace (Rados, 1996). Critics, however, argue that competition diverts attention and resources from service provision to creating and maintaining competitive advantage.

\section{Non-profit brand image}

In recent decades marketing concepts have been acknowledged to play a key role in the achievement of non-profit organizational objectives (Rees, 1998). The marketing discipline has contributed to knowledge relating to non-profit competition, particularly in terms of how commercial marketing concepts - such as organizational brand image - can contribute to the achievement of differentiation and competitive advantage.

Saxton (1995) advocated the value of non-profit brands and emphasized the importance of building brand awareness and trust amongst the market and aligning brand image attributes 
with needs and motivations of potential donors and volunteers. Positive attitudes towards non-profit brands have been linked with higher levels of donation behavior (Bendapudi, Singh and Bendapudi, 1996). Chiagouris (2005) goes further to state that "a compelling brand image is more important to non-profits than commercial sector companies” (p.33) and that an effective brand image can significantly increase numbers of donors, members and volunteers. In recognizing the importance of brands for the non-profit sector, Ewing and Napoli (2005) developed a tool to measure non-profit brand orientation. They suggest that non-profit organizations need to be fully in tune with stakeholder needs and that brand-related activities should be fully coordinated in order to maximize brand awareness and optimize organizational performance. They also emphasize the importance of considering brand preference and likability amongst the stakeholders and the affect this has on the achievement of organizational goals. In addition to measuring their own organization's non-profit brand orientation, the authors suggest the scale be used to measure the non-profit brand orientation of competitor organizations to identify weaknesses in their competitive brand management practices.

Randle and Dolnicar conducted multiple studies of volunteers and volunteer organizations using segmentation techniques to investigate the competitive structure of the volunteer market (2007a; 2009). Findings indicate that volunteers categorize non-profit organizations in terms of generic brand images and that individuals can differ in terms of which brand image they assign an organization. Organizations compete with each other when they are assigned the same generic brand image by the one individual, because in this case they could be considered interchangeable in terms of the volunteering experience.

Remaining unknown is whether two organizations perceived by an individual to have different brand images could potentially share volunteers because the two experiences are seen as different and complimentary. This is important to know because of the large 
proportion of volunteers that give their time to more than one organization. If this is the case it would reveal opportunities for new branding strategies which have proven successful in the commercial sector but have not been extended to the non-profit sector, for example organizational co-branding or leveraging brand loyalty or tribalism for one organization to generate support for a complimentary organization (Jurisic and Azevedo, 2011). Ultimately, if synergies can be harvested by combining volunteer marketing efforts non-profit organizations could make more efficient use of their marketing budgets and fill the need for volunteers to provide important social services.

\section{METHODOLOGY}

\section{Data collection}

Data was collected in Australia using a permission-based online panel. The panel is recruited through various methods (such as shopping center intercepts, newspaper advertisements and online) in order to minimize recruitment methods bias. Given our aim to identify clusters of the population which are inherently different from one another (not estimate the size of these clusters), the sample necessarily included maximum population heterogeneity. The data set included Australian residents who associated with 14 different cultural backgrounds and was therefore an ideal sample to investigate the present research question.

\section{Measures}

Volunteering organizations 
Respondents were asked about their perceptions of eight different volunteering organizations: the Red Cross (RC), St.Vincent de Paul (StV), the State Emergency Service (SES), the Rural Fire Service (RFS), Surf Life Saving (SLS), Rotary (Rot), Parents and Citizens Associations $(\mathrm{PnC})$ and Bushcare (BC). The organizations were chosen after consultation with managers in various local, state and federal volunteering agencies and represent a broad range of humanitarian, environmental, emergency services and community-based volunteering organizations.

\section{Image perceptions}

Perceptions were measured using 18 organizational image attributes: prestigious, political, upper class, loving, mainly for men, popular, Aussie, outdoorsy, heroic, supports local community, honest, compassionate, caring, well organized, reliable, committed, reputable and positive influence. These attributes were based on Venable, Rose, Bush and Gilbert's (2005) non-profit brand personality scale but modified for use in the Australian context. This was done using C-OAR-SE procedure for scale development (Rossiter, 2002), which prescribes that expert judges identify the main components of an "abstract formed object” (p.312), such as brand personality, with the assistance of interviews with the relevant raters (Australian residents from a range of different cultural backgrounds). Items are then formulated for each component, which in this case were the 18 brand personality attributes. Participants indicated by ticking (or not ticking) the appropriate box whether they felt each item described each organization (participants only ticked those attributes that applied to each organization). The list of image attributes was randomly ordered for each respondent to avoid order bias.

\section{Consideration}


Consideration of volunteering organizations was measured to assess the extent to which individuals perceive volunteering as an exclusive or complementary activity. Consideration was measured by presenting the list of eight organizations to respondents and asking "Which of the following organizations would you consider giving unpaid help to?”. Respondents could choose as many of the eight options as applied to them.

\section{Motivations}

Motivations for volunteering were measured for the purposes of understanding and profiling the clusters identified. Participants were presented with a list of 18 motivations for volunteering, which was developed following a series of in-depth interviews with current volunteers, ex-volunteers, volunteer managers and community leaders. The list included motivations which serve different functions as defined by the Volunteer Functions Inventory (VFI, Clary et al, 1998) including values (e.g. It gives the chance to help others); enhancement (e.g. It keeps me active), social (e.g. I can socialize with people who are like me), career (e.g. It will help my career prospects), and protective (e.g. It helps me feel less lonely).

\section{Socio-demographic characteristics}

Socio-demographic information was collected for the purposes of profiling clusters and understanding the characteristics of individuals most likely to volunteer for different organizations. Information collected included age, sex, marital status, household status, education, employment status, income, children and citizenship. For the purposes of targeting individuals through marketing campaigns a number of media usage questions were also asked including television viewing, radio listening and newspaper and magazine readership.

\section{Analysis}


Data was analyzed using the Perceptions Based Market Segmentation (PBMS) approach (Buchta, Dolnicar and Reutterer, 2000; Mazanec and Strasser, 2000). This approach uses an individual's perceptions of multiple objects (volunteering organizations) to identify generic images of the objects. These generic images can be viewed similarly to "brand archetypes" (Mark and Pearson, 2002) because they represent a particular type of non-profit organization that is likely to appeal to volunteers with specific needs. Once these are identified the association of each object with each generic image is analyzed and competitive relationships can be established. PBMS relies on one single analysis to derive positioning, segmentation and competition analysis, thus ensuring integrated treatment of these three areas.

All brand perceptions (8 brands x 18 attributes) were stacked into one data set, temporarily ignoring the respondent and considering only the evaluation (image attributes selected) and the object (volunteering organization). Because image perceptions were collected using binary answer format any missing data could be coded as zero without biasing the data. As will be discussed later, these missing values were captured by one single cluster resulting from the analysis.

Neural gas partitioning (Martinetz and Schulten, 1994) was used as the clustering algorithm. Clustering was computed in R version 2.15.2 (R Development Core Team, 2012) using package flexclust (Leisch, 2006, 2010). Multiple segmentation alternatives (ranging from three to eight clusters) were considered in terms of their interpretive insight and managerial usefulness. For the purposes of this investigation the eight cluster solution was chosen because the key aim was to investigate competition and collaboration potential, and solutions with lower numbers of clusters (e.g. the six cluster solution) were not sufficiently finegrained to detect competition or collaboration. This subjective approach is acceptable if data structure is weak, which is often the case with survey data. 


\section{RESULTS}

Eleven point eight per cent of the sample $(n=168)$ indicated they would not consider volunteering for any of the eight organizations listed, while $19.5 \%$ would consider volunteering for only one $(n=276)$. Twenty-two point four per cent would consider two $(n=317), 19.7 \%$ three $(n=279)$ and $12.4 \%$ four organizations $(n=175)$. A small percentage would consider volunteering for more organizations than this, with 5.5\% considering five $(n=78), 3.5 \%$ considering six $(n=49), 1.6 \%$ considering seven $(n=22)$ and $3.6 \%$ considering all eight $(n=51)$. These results are illustrated at Figure 1.

Insert Figure 1 about here.

The large percentage of the sample that would volunteer for more than one organization suggests there is value in investigating the combinations of volunteering organizations being considered in order to answer the present research question. Results are presented in three stages. Firstly, generic brand image positions of volunteering organizations are presented (Figure 2) and their relative proximity to each other (Figure 3). Secondly, the similarity of brand image perceptions is examined by considering the extent to which two brands are assigned to the same position more frequently than would be expected. Based on this analysis volunteering organizations are grouped according to their perceived similarity. Finally, we examine whether consideration sets imply competitive or complementary relationships within and between these groups of organizations (Figures 4-6). 


\section{Generic brand image positions of non-profit organizations}

Figure 2 provides detailed profiles of the eight clusters that emerged. For each cluster two pieces of information are provided per attribute: the percentage of the population that selected the attribute across all brands (represented by the horizontal line with a dot at the end) and the percentage of that cluster that selected the attribute (represented by the horizontal bar).

Clusters are interpreted by evaluating differences between the total population (the dot) and the cluster (the bar).

Clusters 1 and 8 should be interpreted with care. They collect response patterns which are characterised by high level of overall agreement and disagreement respectively. At least in part these clusters capture response styles rather than true image perceptions of respondents. Therefore, for the purposes of this analysis they are not interpreted in detail.

Cluster 2 is characterised by one perception more than average: being local, and is therefore referred to as the "Locals”. Cluster 3 is characterised by two attributes: caring and compassionate, and has therefore been given this name. Cluster 4 is male, outdoorsy, heroic and Aussie, and is referred to as the “Aussie heroes”. Cluster 5 is political, organized, committed and reputable. This is a distinctly different position to those identified thus far and is referred to as “Organized and reputable”. Cluster 6 represents a brand image associated with a number of attributes including local, loving, popular, honest, compassionate, caring, organized, reliable, committed, reputable and influential. We refer to this cluster by the characteristics distinct from the other clusters: “Loving and honest”. Finally, cluster seven is similar to six, with the main difference being that that it is seen as male and heroic, but not loving. We refer to this cluster as the "Local heroes". 
Insert Figure 2 about here.

Figure 3 illustrates the spatial proximity of the clusters (indicated by numbers) and the relative positions of the organizations (indicated by the letters). The response style clusters (1 and 8) form extreme points along the horizontal dimension. The clusters containing the heroic component (4 and 7) are located adjacent to one another and the State Emergency Service, the Rural Fire Service and Surf Life Saving are all positioned close to these. Rotary is located close to the "Organized and Reputable” position (5) and the Parents and Citizen’s Association is closest to the "Caring and Compassionate" position (3).

Insert Figure 3 about here.

Figures 2 and 3 graphically illustrate that different non-profit brand images exist and that some organizations are associated more strongly with certain brand image positions than others, permitting conclusions to be drawn about how they are perceived by the population (see also Randle and Dolnicar, 2009).

\section{Perceptual similarity or competition between volunteering brands}

Next, analysis was performed to explore how often different organizations appeared in the same cluster for the same individual. A permutation test for no more competition than occurring by chance yields a number of instances where figures are significantly larger than expected. This means that they are perceived by the individual similarly, and therefore form one grouping of like-organizations. The first group perceived similarly includes Parents and 
Citizens Associations and Rotary. The second group perceived similarly includes the State Emergency Service, the Rural Fire Service, Bushcare and Surf Life Saving. Finally, the third grouping includes St Vincent de Paul and the Red Cross. Note that these similarities or relationships of perceptual competition are derived purely from respondent perceptions, not from preferences or consideration. The next and final analysis examines stated consideration, based on the newly identified groupings of similar organizations: respectively termed the (1) Heroes, (2) Saviors and (3) Locals.

\section{Potential for collaboration between organizations}

The final stage of analysis explored whether organizations are in fact competing with each other, which involved participants’ stated consideration of volunteering organizations. For this analysis we include individuals who selected between one and four organizations, and exclude those who selected no organizations (zero selected) or most organizations (5+ selected). The resulting sample size is 771 .

Results indicate that individuals who would consider volunteering for an organization in the Heroes group are less likely than expected to volunteer for organizations seen as Saviors or Locals. This is not the case, however for organizations belonging to the Locals or Saviors. Individuals who would consider volunteering for a Savior organization are more likely than expected to also consider volunteering for a Local organization.

The relationships between the three groupings of organizations are depicted graphically as Figures 4-6. In each of these figures, the numbers across the top and down the side of the charts indicate the number of organizations chosen within that group. There are three rows of blocks, representing zero, one and two or more organizations chosen from the x-axis group (labelled on the left hand side of the chart). Each row also contains three blocks representing 
zero, one and two organizations chosen from the y-axis group (labelled at the top of the chart). The size of the blocks represents the number of people who chose that combination of organization groups.

Striped blocks indicate choices made by respondents that are not independent of each other. Blocks with horizontal stripes indicate a positive relationship; blocks with vertical stripes indicate a negative relationship. The darker the stripes (i.e. black versus grey) the stronger the deviation from independence and the higher degree of competition. White blocks with no stripes indicate choices unrelated to each other. In other words, they are made independently of each other and therefore can be considered potentially collaborative partnerships.

Figure 4 depicts the degree of independence between the number of organizations chosen in the Saviors group and the number of organizations chosen in the Heroes group. The high percentage of striped blocks means that if individuals choose organizations in the Heroes group they are unlikely to choose organizations in the Saviors group. For example, the horizontally striped boxes in the top right corner and bottom left corner of the chart indicate that individuals who would consider volunteering for two Saviors organizations are unlikely to consider volunteering for a Heroes organization, and vice versa. These people are interested in only one type of volunteering organization and will choose between organizations perceived to have this image - essentially forcing them to compete with each other.

Insert Figure 4 about here.

Figure 5 illustrates the degree of competition between the Heroes and the Locals. Results present similarities to Figure 4, with the horizontally striped blocks in the top right and 
bottom left corners indicating that individuals who consider volunteering for multiple organizations in one grouping are unlikely to consider organizations in the other grouping.

Insert Figure 5 about here.

Figure 6 shows the relationship between the Saviors and the Locals. The lack of any striped blocks indicates that choices made when considering these two organization types are independent of each other. This suggests that these two groupings of organizations could potentially collaborate to attract and share volunteers, because it is unlikely to adversely affect each other's overall volunteering levels.

Insert Figure 6 about here.

Subsequent analysis of the socio-demographic characteristics and media usage of individuals who consider multiple organizations reveals insight into the marketing strategies likely to be effective in attracting them. If, for example, we examine individuals who would consider volunteering for at least one of the Locals organizations and at least one of the Saviors organizations ( $n=349)$ and compare them to the rest of the sample ( $n=848$, excludes the 218 participants who selected no or all organizations) we find significant differences for a number of characteristics at the $99 \%$ level. Results have been Bonferroni corrected to account for multiple testing. This segment is profiled below and represents the types of people who could be targeted by collaborative recruitment campaigns. 
They are significantly more likely to be female (71\% compared with 53\%), between the ages of $26-45$ (63\% compared with 53\%), married (51\% compared with 37\%) and have children (50\% compared with 38\%). In terms of why they volunteer their motivations are multifaceted. Compared to the rest of the sample they are more likely to volunteer because it gives them a chance to help others (78\% compared to 66\%) and give something back to society (78\% compared to $61 \%$ ), it enables them to support an important cause (71\% compared to 56\%) and meet different types of people (64\% compared to $46 \%$ ), it makes them feel like they are doing a good job (63\% compared to 49\%) and they believe it will help their community (63\% compared to 52\%). Regarding media usage they are more likely to listen to easy listening stations on the radio (60\% compared to 45\%), read cooking magazines (63\% compared with 50\%) and women fashion/lifestyle magazines (67\% compared to 52\%); and read their local newspaper (93\% compared to 85\%).

\section{DISCUSSION AND CONCLUSIONS}

The aim of this study was to determine whether volunteering organizations necessarily compete for volunteers or whether, based on their perceived brand image, they are seen as complementary. Results indicate there is no one optimal competitive or collaborative approach suitable for all non-profit organizations. Instead, the appropriate strategy depends on an organization's own brand image and that of the other organizations operating in the sector. Volunteers who consider organizations with particular brand images - especially the Heroes image - are unlikely to donate time to other volunteering organizations. However, volunteers who would consider organizations with alternative brand images - such as the 
Locals or Saviors image - are also likely to consider other organizations and can therefore be considered compatible.

Individuals who would consider volunteering for more than one grouping of organizations also differ in their personal characteristics and motivations. This insight should underpin the design of any joint recruitment strategies between volunteering organizations. For example, in relation to a Locals and Saviors collaboration, marketing messages should reinforce their volunteering motivations which include both altruistic motivations (e.g. wanting to help others and give back to their community) and egoistic motivations (e.g. wanting to meet new people and gain personal satisfaction from their work). The fact that multiple motivations are relevant suggests that multiple communications including a variety of different benefits would be appropriate. Differences in media usage patterns can also be used to determine appropriate communication channels. For a Locals/Saviors collaboration, these should include local newspapers, easy listening radio stations and cooking or women’s lifestyle magazines.

Theoretically, findings add to knowledge regarding the role of organizational brand image for the non-profit sector, the structure of the volunteering market and the decision process individuals go through when considering volunteering alternatives. To this point, most investigations of non-profit brand image have implicitly assumed an environment of competition and the need for organizations to develop positive and strong brand images in order to differentiate themselves from competitors and achieve competitive advantage. Whilst the present results support the importance of brand image for non-profit organizations, it challenges the generic assumption of competition and suggests that marketing strategies be developed according to volunteer consideration sets, which are influenced by the comparative brand images of the organizations operating in a particular marketplace. 
Practically, results reinforce to volunteer managers the importance of a clear understanding of their own perceived brand image and that of other organizations operating in the sector. Organizations for which a collaborative marketing approach to volunteer recruitment is optimal have potentially significant benefits to gain. These include the ability to share marketing knowledge between organizations that typically lack scientific marketing expertise and experience, and pooling financial resources to make more effective use of limited marketing budgets. Ultimately, the result will be more volunteers who are invaluable in providing important social services.

\section{LIMITATIONS AND FUTURE RESEARCH}

A limitation of this study is the use of consideration of volunteering organizations as a proxy for actual volunteering behavior. This was considered reasonable for the present analysis because we know that a large proportion of the population not only considers multiple volunteering alternatives but also volunteers for multiple organizations. It is likely that the combination of organizations volunteered for is a reflection of the consideration set. Similar analysis using actual volunteering behavior data would strengthen the findings presented here.

This study is also limited to the eight organizations selected to represent a range of non-profit volunteering opportunities. Given the extremely wide range of organizations operating in the non-profit sector may be possible that additional generic image positions apply which have not been identified here. Further studies which include more and different organizations would be useful in broadening the practical usefulness of findings. Also, the brand image attributes used for this study were modified for use in the Australian context, and some 
attributes which have contributed to the formation of the generic image positions (most obviously “Aussie”) would hold less relevance for organizations operating in countries other than Australia.

This study of non-profit brand image also highlights various avenues for future research in order to better understand the role of brand image in the third sector and how non-profits can develop the brand images that are most useful in achieving organizational goals. As previously mentioned, the generic brand image positions referred to in the present study relate closely to the notion of "brand archetypes", which have received attention in the context of commercial marketing but as yet have received little attention in the non-profit sector. Future research examining the extent to which brand archetypes exist and can be harnessed by managers of non-profit organizations would be a useful avenue for further investigation. This could also include, from the organizational perspective, the possible effectiveness of alternative brand strategies such as co-branding; or from a consumer behavior perspective, studies relating to brand tribalism and the potential for this to be harnessed for the purposes of volunteer recruitment and retention. 


\section{REFERENCES}

Andreasen, A. R., \& Kotler, P. (2003). Strategic Marketing for Non-profit Organizations (6th ed.).Prentice Hall Upper Saddle River, NJ.

Australian Bureau of Statistics. (2010). Voluntary Work Australia. Retrieved from http://www.ausstats.abs.gov.au/Ausstats/subscriber.nsf/0/404350EEC6509985CA257 9580013177A/\$File/44410_2010.pdf

Bendapudi, N., Singh, S. N., \& Bendapudi, V. (1996). Enhancing Helping Behavior: An Integrative Framework for Promotion Planning. Journal of Marketing, 60(3), 33-49.

Broadbridge, A., \& Horne, S. (1996). Volunteers in Charity Retailing: Recrutiment and Training. Non-profit Management and Leadership, 6(3), 255-270.

Buchta, C., Dolnicar, S., \& Reutterer, T. (2000). A nonparametric approach to perceptionsbased market segmentation applications.Springer Verlag Berlin.

Bureau of Labor Statistics. (2007). Volunteering in the United States, 2006. Retrieved 11 May, 2007, from http://www.bls.gov/news.release/pdf/volun.pdf

Bussell, H., \& Forbes, D. (2002). Understanding the Volunteer Market: The What, Where, Who and Why of Volunteering. International Journal of Non-profit and Voluntary Sector Marketing, 7(3), 244-257.

Chiagouris, L. (2005). Non-profit Brands Come of Age. Marketing Management, 14(5), 3033.

Clary, E. G., Ridge, R. D., Stukas, A. A., Snyder, M., Copeland, J., Haugen, J., et al. (1998). Understanding and Assessing the Motivations of Volunteers: A Functional Approach. Journal of Personality and Social Psychology, 74(6), 1516-1530.

Dolnicar, S., \& Lazarevski, K. (2009). Marketing in non-profit organizations: and international perspective. International Marketing Review, 26(3), 275-291.

Dolnicar, S., \& Randle, M. (2006). Who Donates Time to the Benefit of Environmental and Animal Rights? Profiling Volunteers From an International Perspective. Paper presented at the Australasian Non-profit and Social Marketing Conference CD Proceedings, Newcastle, New South Wales.

Dolnicar, S., \& Randle, M. (2007a). The International Volunteering Market: Market Segments and Competitive Relations. International Journal of Non-profit and Voluntary Sector Marketing, 12(4), 250-370.

Dolnicar, S., \& Randle, M. (2007b). What Moves Which Volunteers? Psychographic Heterogeneity Among Volunteers in Australia. Voluntas: International Journal of Voluntary and Non-profit Organizations, 18(2), 135-155.

Ewing, M. T., \& Napoli, J. (2005). Developing and Validating a Multidimensional Non-profit Brand Orientation Scale. Journal of Business Research, 58(6), 841-853.

Guo, C., \& Acar, M. (2005). Understanding Collaboration Among Non-profit Organizations: Combining Resource Dependency, Institutional, and Network Perspectives. Nonprofit and Voluntary Sector Quarterly, 34(3), 340-361.

Haski-Leventhal, D., \& Meijs, L. C. P. M. (2011). The volunteer matrix: positioning of volunteer organizations. International Journal of Non-profit and Voluntary Sector Marketing, 16(1), 127-137. 
Hibbert, S., Piacentini, M., \& Al Dajani, H. (2003). Understanding Volunteer Motivation for Participation in a Community-Based Food Cooperative. International Journal of Nonprofit and Voluntary Sector Marketing, 8(1), 30-42.

Jurisic, B., \& Azevedo, A. (2011). Building customer - brand relationships in the mobile communications market: The role of brand tribalism and brand reputation Journal of Brand Managment, 18(1), 349-366.

Kaplan, M. (1986). Cooperation and Coalition Development Among Neighborhood Organizations: A Case Study. Journal of Voluntary Action Research, 15(4), 23-34.

Lawler, E. J. (2001). An Affect Theory of Social Exchange. American Journal of Sociology, 107(2), 321-352.

Leisch, F. (2006). A Toolbox for K-Centroids Cluster Analysis. Computational Statistics and Data Analysis, 51(2), 526-544.

Leisch, F. (2010). Neighborhood graphs, stripes and shadow plots for cluster visualization. Statistics and Computing, 20(4), 457-469.

Lindenberg, M., \& Dobel, J. P. (1999). The Challenges of Globalization for Northern International Relief and Development NGOs. Non-profit and Voluntary Sector Quarterly, 28(4), 4-24.

Lyons, M., \& Passey, A. (2005). Giving Australia: Research on Philanthropy in Australia: Department of Families, Community Service and Indigenous Affairs.

Mark, M., \& Pearson, C. (2002). The Hero and the Outlaw: Building Extraordinary Brands through the Power of Archetypes.McGraw-Hill New York, NY.

Martinetz, T., \& Schulten, K. (1994). Typology Representing Networks. Neural Networks, 7(5), 507-522.

Mazanec, J., \& Strasser, H. (2000). A Non-Parametric Approach to Perceptions-Based Market Segmentation: Foundations.Springer Berlin.

Pietroburgo, J., \& Wernet, S. P. (2004). Joining Forces, Fortunes and Futures: Restructuring and Adaptation in Non-profit Hospice Organizations. Non-profit Management and Leadership, 15(1), 117-137.

Provan, K. G., Isett, K. R., \& Milward, H. B. (2004). Cooperation and Compromise: A Network Response to Conflicting Institutional Pressures in Community Mental Health. Non-profit and Voluntary Sector Quarterly, 33(3), 489-514.

R Development Core Team. (2012). R: A Language and Environment for Statistical Computing. Vienna, Austria: R Foundation for Statistical Computing, http://www.Rproject.org.

Rados, D. L. (1996). Marketing for Non-profit Organizations (2nd ed.).Auburn House London.

Randle, M., \& Dolnicar, S. (2009). Understanding the Australian Environmental Volunteering Market - A Basis for Behavioural Change and a Sustainable Future. Australasian Marketing Journal, 17(4), 192-203.

Reed, P. B., \& Selbee, L. K. (2000). Distinguishing Characteristics of Active Volunteers in Canada. Non-profit and Voluntary Sector Quarterly, 29(4), 571-592.

Rees, P. L. (1998). Marketing in the UK and US Not-for-Profit Sector: The Import Mirror View. The Service Industries Journal, 18(1), 113-131. 
Rossiter, J. R. (2002). The C-OAR-SE Procedure for Scale Development in Marketing. International Journal of Research in Marketing, 19(4), 305-335.

Sargeant, A. (2005). Marketing Management for Non-profit Organisations (2nd ed.).Oxford University Press Oxford, UK.

Sargeant, A., \& Jay, E. (2004). Fundraising Management: Analysis, Planning and Practice.Routledge Oxford, UK.

Saxton, J. (1995). A Strong Charity Brand Comes From Strong Beliefs and Values. The Journal of Brand Management, 2(4), 211-220.

Schlesinger, T., \& Nagel, S. (2013). Who will volunteer? Analysing individual and structural factors of volunteering in Swiss sports clubs. European Journal of Sport Science.

Starnes, B. J., \& Wymer, W. W. (2001). Conceptual Foundations and Practical Guidelines for Retaining Volunteers Who Serve in Local Non-profit Organizations: Part 2. Journal of Non-profit and Public Sector Marketing, 9(1-2), 97-118.

Venable, B. T., Rose, G. M., Bush, V. D., \& Gilbert, F. W. (2005). The Role of Brand Personality in Charitable Giving: An Assessment and Validation. Journal of the Academy of Marketing Science, 33(3), 295-312.

Wymer, W. W. (1997). Segmenting Volunteers Using Values, Self-Esteem, Empathy, and Facilitation as Determinant Variables. Journal of Non-profit and Public Sector Marketing, 5(2), 3-28.

York, a., \& Zychlinski, E. (1996). Competing Non-profit Organizations Also Collaborate. Non-profit Management and Leadership, 7(1), 15-27. 


\section{FIGURES}

Figure 1: Number of volunteering organizations respondents would consider volunteering for

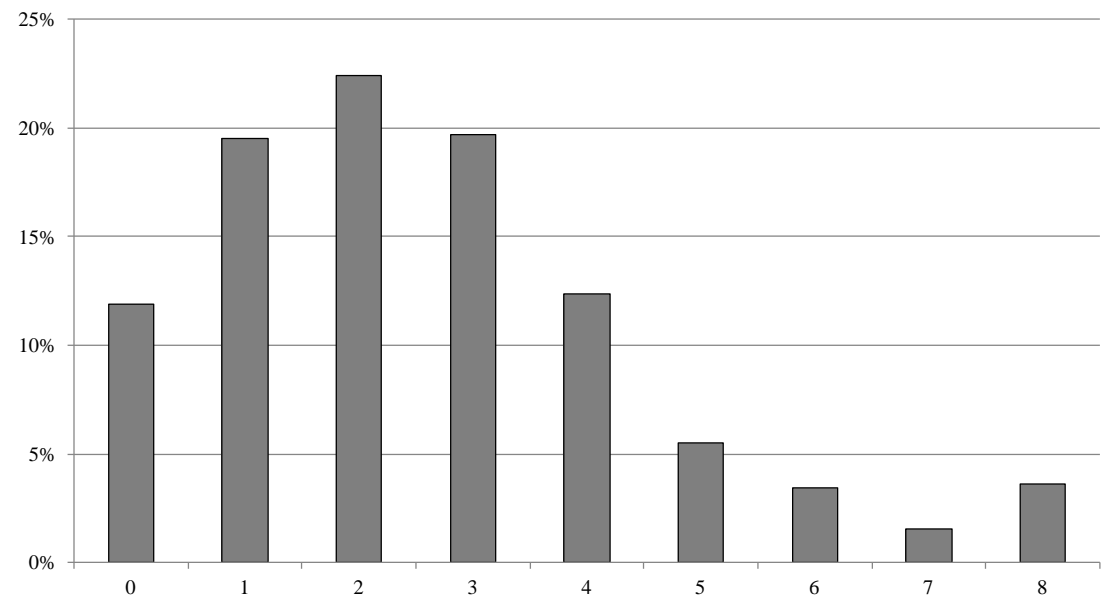


Figure 2: Attributes of the eight generic brand image positions

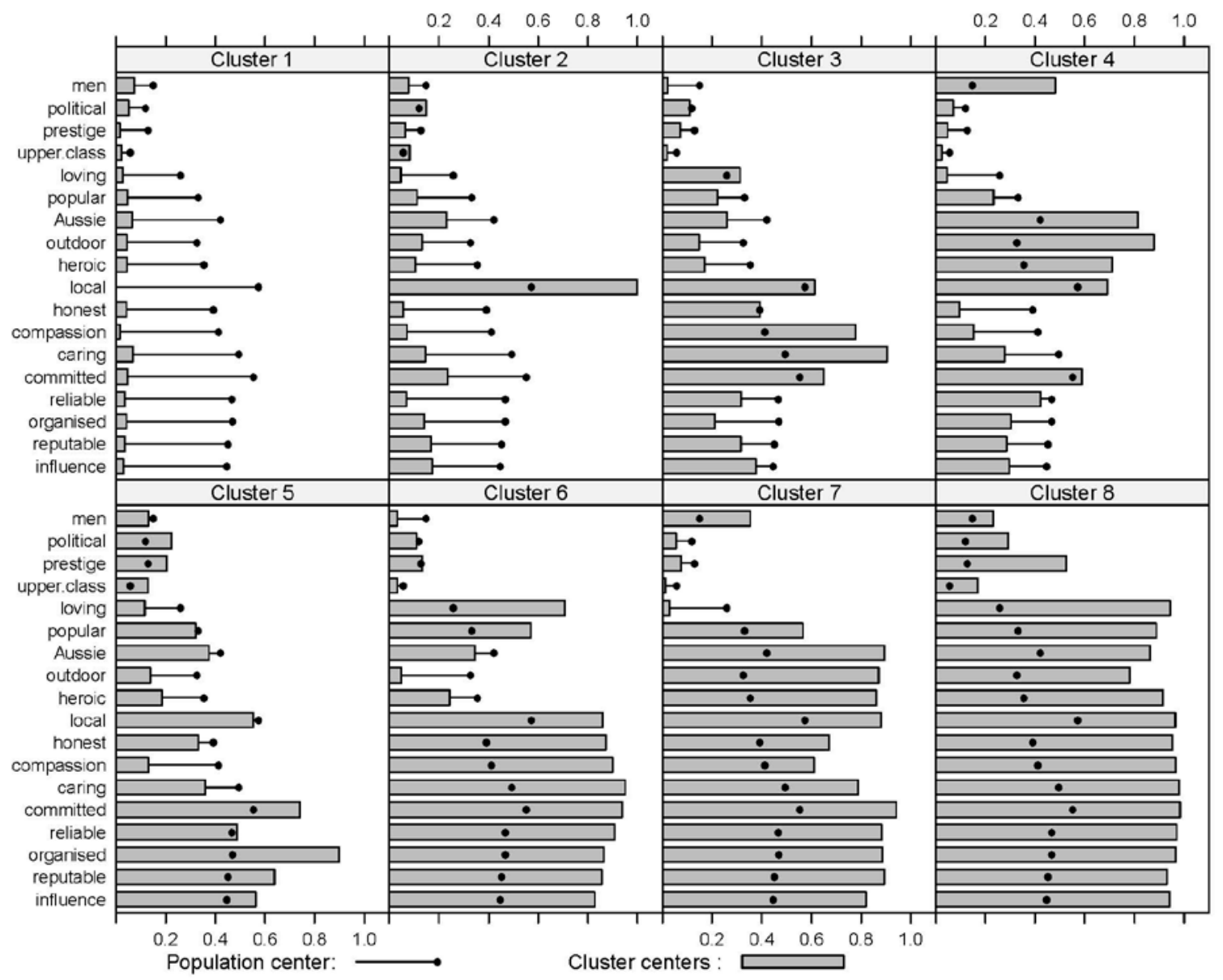


Figure 3: Proximity of generic brand image positions and organizations

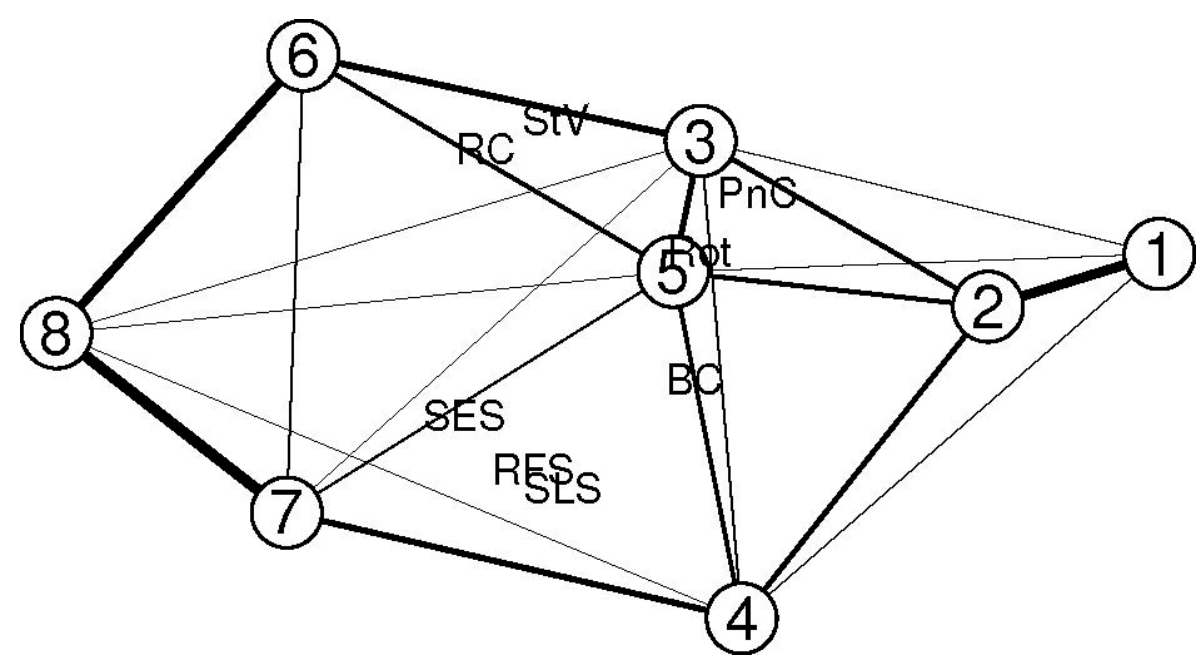


Figure 4: Competition between the Heroes and the Saviors

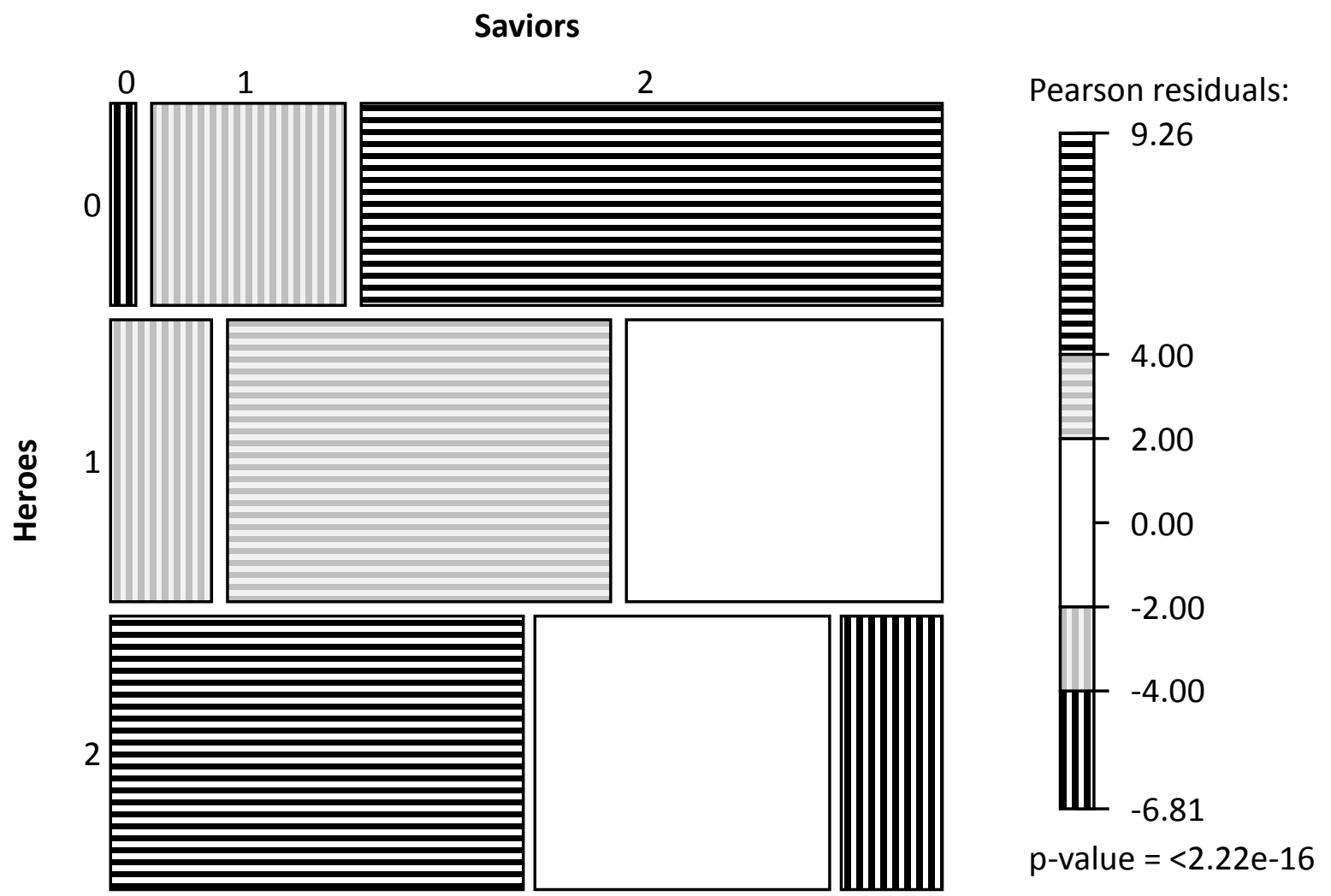


Figure 5: Competition between the Heroes and the Locals

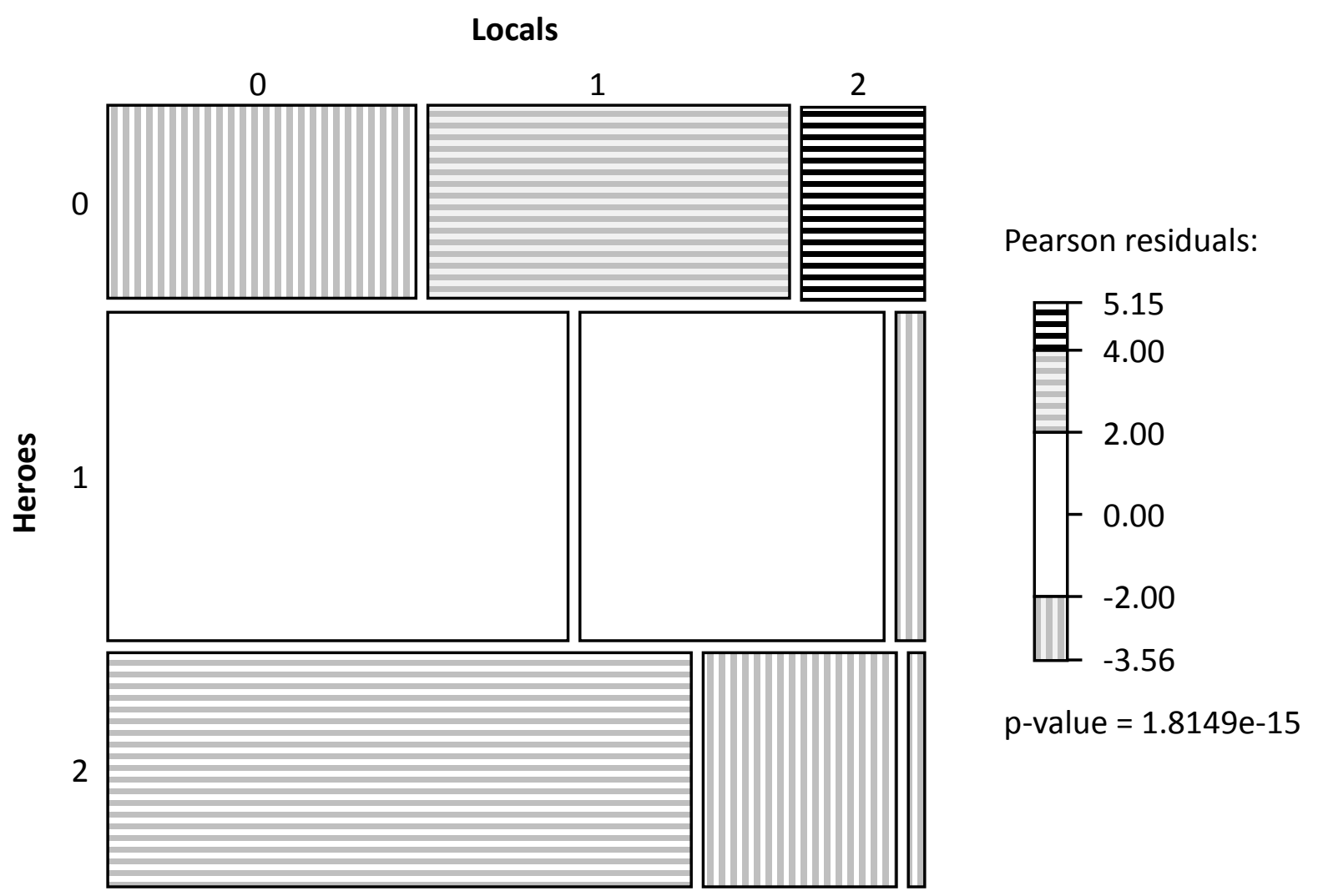


Figure 6: Competition between the Locals and the Saviors

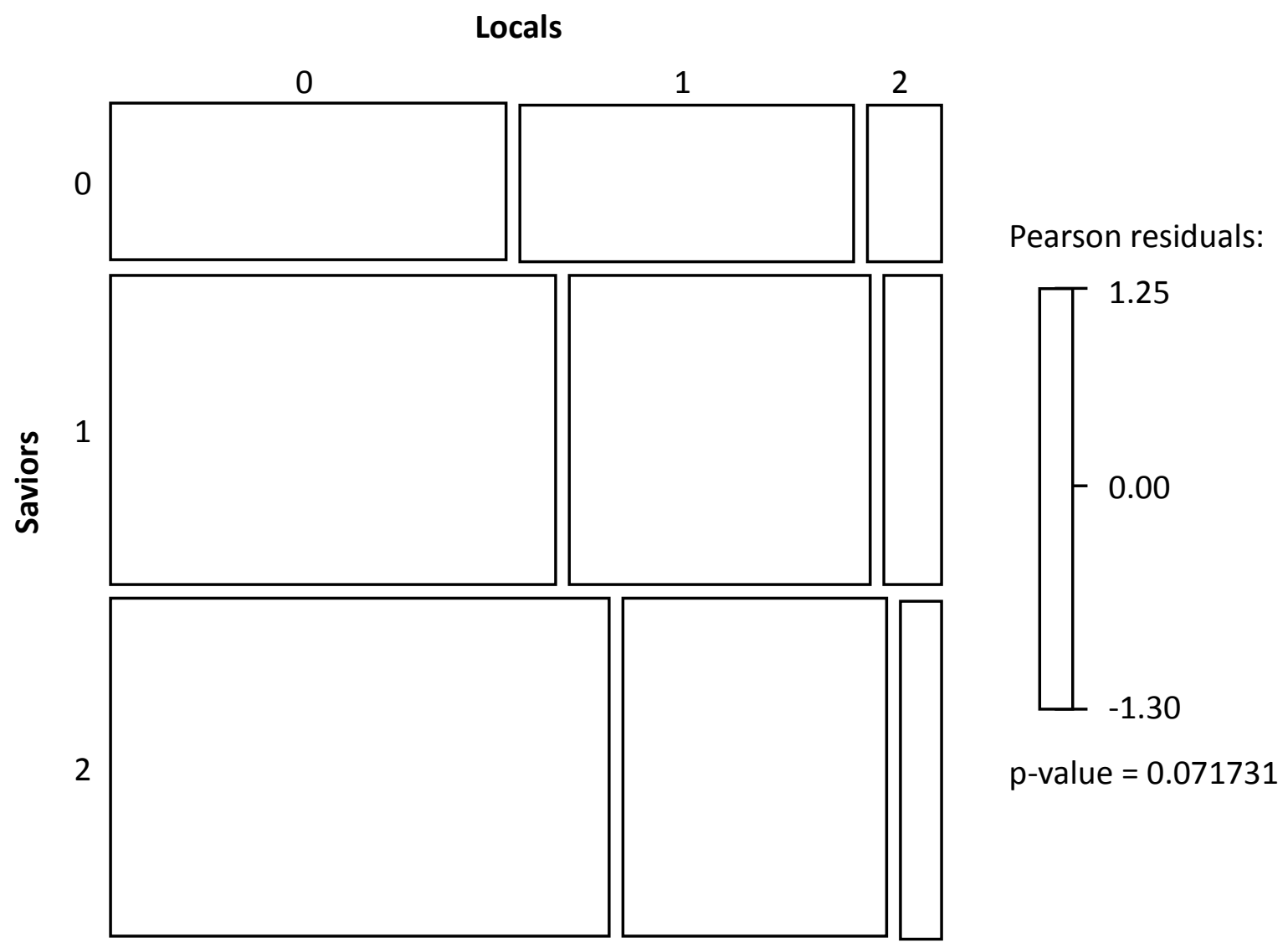

